\title{
كثاف الناشرين
}

• دار الحسيني للطباعة والنشر والتوزيع ivr

• دار الحكمة للطباعة والنشر و التوزيع 191 6101

$$
\text { • د دار حميثز اللنشر }
$$

VT ت • دار ديوان العرب للنشر والتوزيع

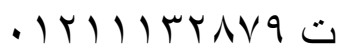

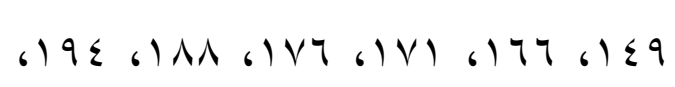

rov • دار زحمة كتاب

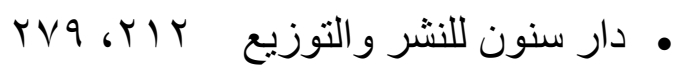

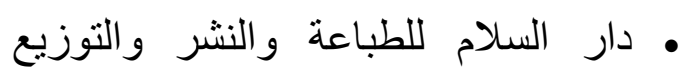

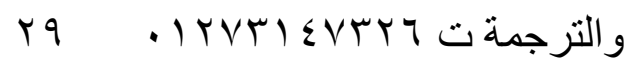

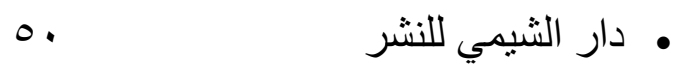
• دار صفصافه للنشر و التوزيع و الدر اسات YN) 6 YOI

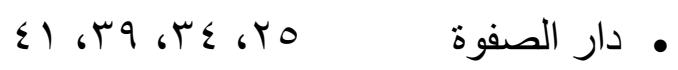

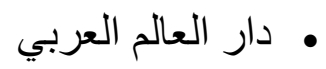

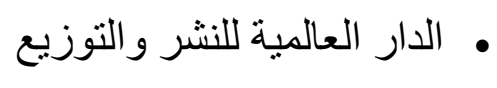

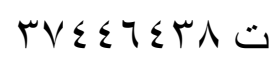

$\mid M$

• دار العلم والإيمان للنشر والتوزيع $11 V_{6} 1.69$

$$
\begin{aligned}
& \text { • دار العين للنشر }
\end{aligned}
$$

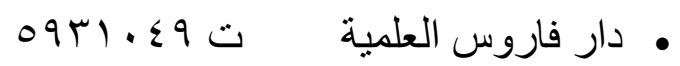

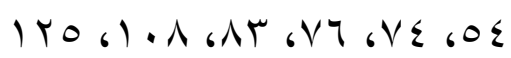

$$
\begin{aligned}
& \text { • أطلس للنشر و الإنتاج الإعلامي } \\
& \text { ت }
\end{aligned}
$$

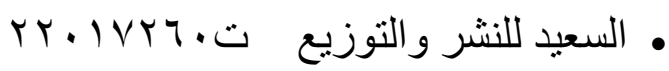

$$
\begin{aligned}
& \text { rTh 6TY ITH }
\end{aligned}
$$

• بلو مانيا للنشر و التوزيع

$$
\text { . Ir.人Ат人Атт }
$$

.

YV9, TYE, TYV 6 YTY • بيت الياسمين للنشر والتوزيع ت • جامعة الدول العربية، معهد البحوث و والدر اسات العربية

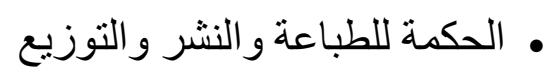
. r

111 6 10 ،

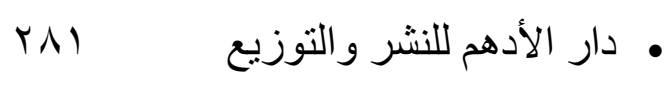

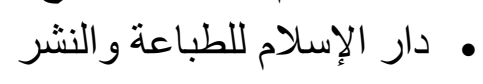
$174610.61 \leqslant 7$

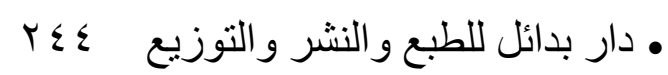

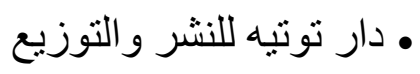
ITYOVTT.7T

YVV G $T \leq \Lambda, Y .0$

VV • دار الثقافة الجديدة

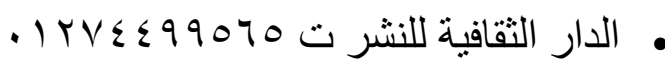
I Y

• دار الجامعة الجديدة

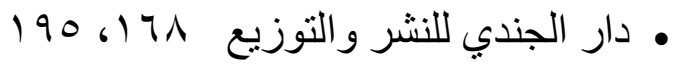

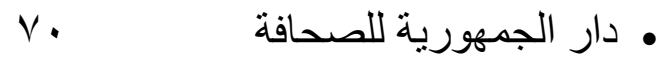




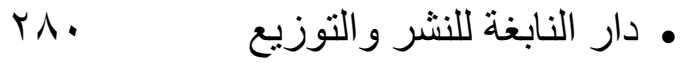
• دار النخبة للطباعة والنشر والتوزيع . I YANANAvo ت

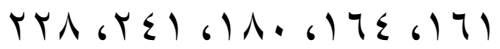
• دار النشر للثقافة والعلوم $r T \leq 61 \cdot 6 r \cdot \Lambda$, IVA

• دار النهضة القومية ت

$6) 1461.769969 \vee 61961 \cdot 601$ 114

• دار نهضة مصر للنشر

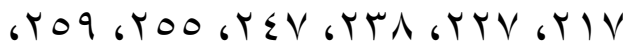
YAV • دار نوبل للنشر و التوزيع

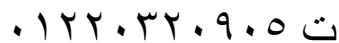

6). 69Y 6 NE 6VT 6 TE 67 6 $149611 \leqslant$

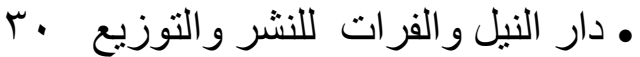
Irr. 19 • الدولية للكتب العلمية • رو ابط للنشر وتقنية المعلومات $1 \leq 1614$

• شعلة الإبداع للطباعة و النشر 19161746101

• كاريزما للنشر و التوزيع . 1.0. 0 . $\leqslant 7 \vee \leqslant ت$

KVO 6YT 6170

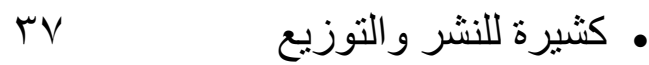

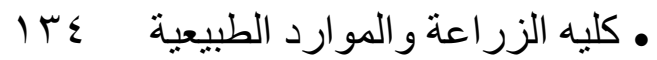
• كيان للنشر و التوزيع

$r \varepsilon$.

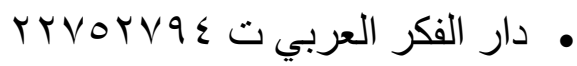

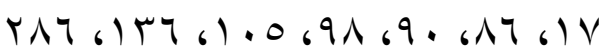
$1 \leqslant Y$ • دار فكرة للنشر والتوزيع

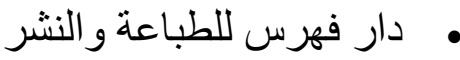
. 1 r. 119077.

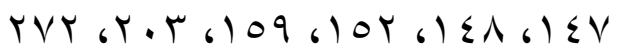

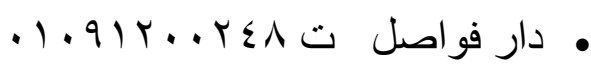
YT. 6 TO 610

• r rvorq9. • ITY TT

Ir. • دار الكتاب العربي

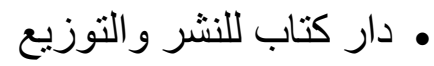

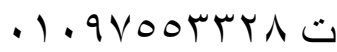

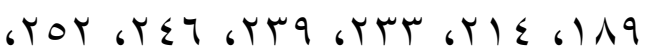
rVI G TON • دار الكتب العلمية للنشر والتوزيع $1 \leqslant r$, $1 \% q$ - rVq0 ت

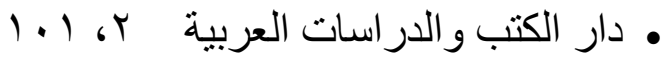
• دار الكتب و الوثائق القومية หัVง ษัマА

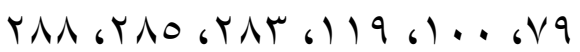

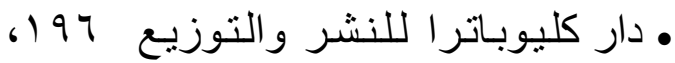

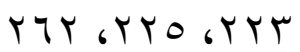

YYq 6 YVT • الدار للنشر والتوزيع • دار المر ايا للإنتاج الثقافي

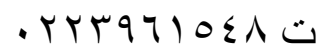

117 6 TVA 674

• دOVVV.VV دار المعارف ت

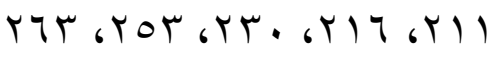

$\wedge$ • دار ميرنا للنشر و التوزيع 


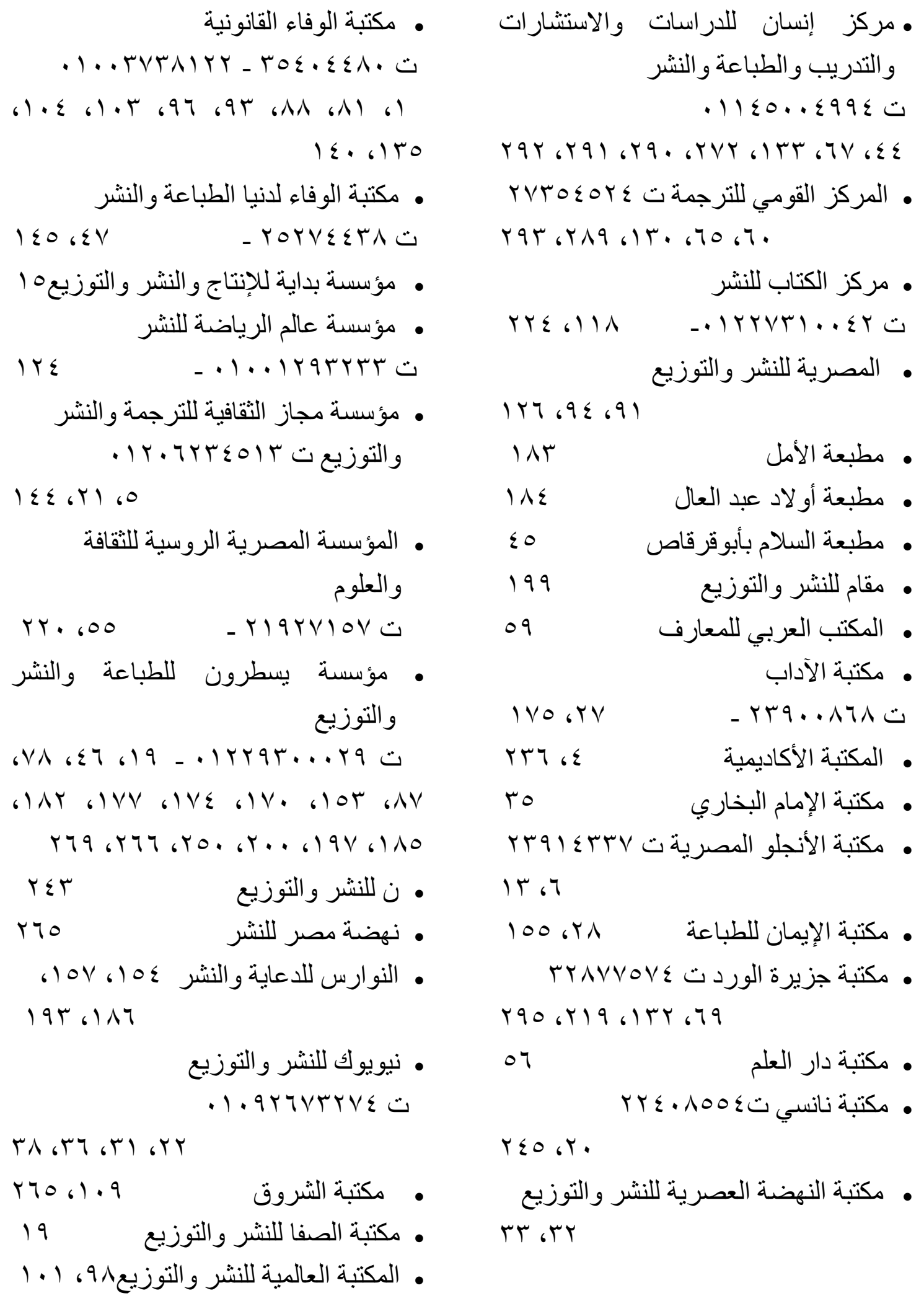

• مكتبة الوفاء القانونية

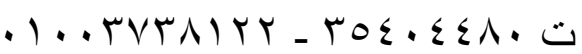

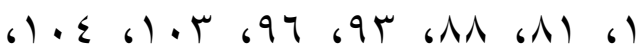

$1 \varepsilon \cdot 61 \mathrm{ro}^{2}$

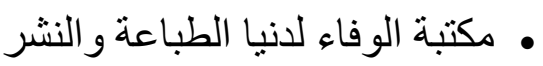
$1 \leqslant 0$ ، $\leqslant V$ - YOTV $\leqslant \leqslant T \wedge ت$

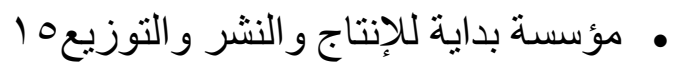

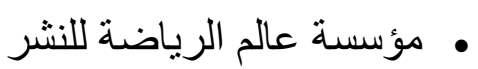
I Y

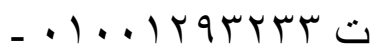
• مؤسسة مجاز الثقافية للترجمة والنشر

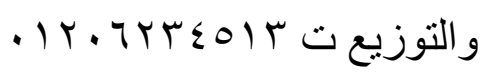

$\left.\mid \leq \varepsilon, Y_{1}\right)_{60}$

• المؤسسة المصرية الروسية للثقافة و العلوم

Yr. 600 - rIGTVIOV ت للطباعة و النشر ، لمر • مؤسسة يسطرون و التوزيع

6VA 6 6) NY , IVY 6IVE 6IV. 6IOH 6 AV r79 6 Y77, rO. 6. . 619V6)10 $r \leqslant r$ • ن للنشر و التوزيع rTO

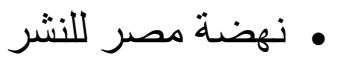

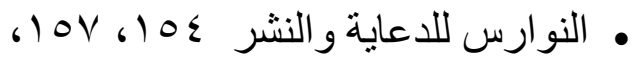
1946117

$$
\text { • ت نيويوك للنشر و التوزيع }
$$

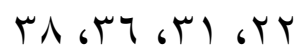

$r 7061.9$

• مكتبة الشروق

19

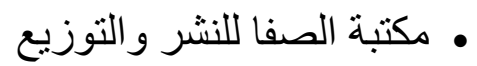

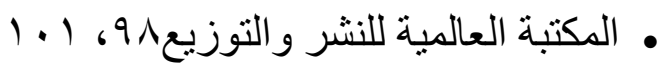

• مركز إنسان للار اسات والاستشارات و التدريب و الطباعة و النشر

$.11 \leq 0 \ldots \leqslant 99 \leq ت$

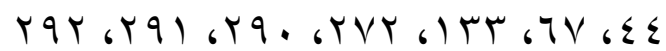

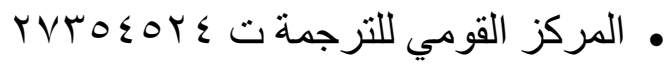

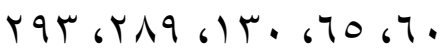

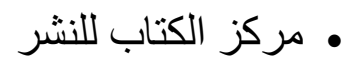

rTE611 ت • المصرية للنشر و التوزيع $147.9 \leq 691$

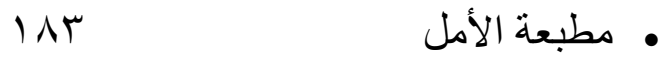

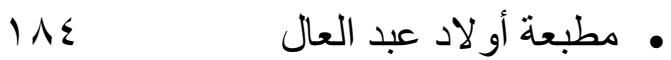

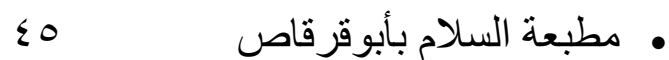

$$
\begin{aligned}
& \text { • 199 مقام للنشر و التوزيع }
\end{aligned}
$$

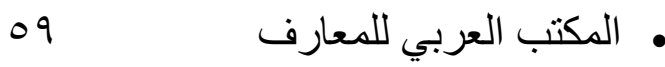

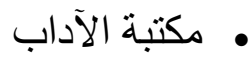

$$
\begin{aligned}
& \text { IVO GV E - Trq..人TA } \\
& \text { צ. דזי } \\
& \text { • }
\end{aligned}
$$

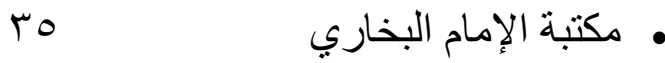

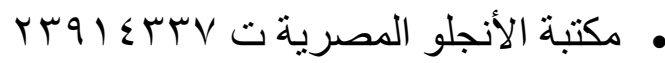

$$
\begin{aligned}
& \text { IT } \\
& \text { • مكتبة الإيمان للطباعة }
\end{aligned}
$$

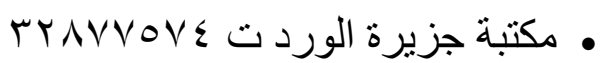
• مكتبة دار العلم

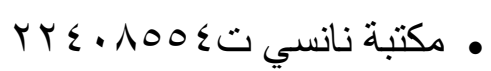
$r \leqslant 0, r$.

• مكتبة النهضة العصرية للنشر والتوزيع

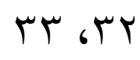




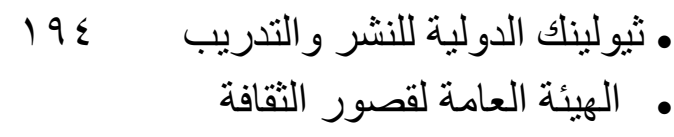

6 TE 6 ह

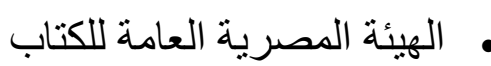
rovVqIrq

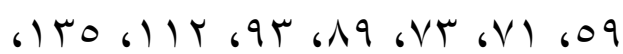

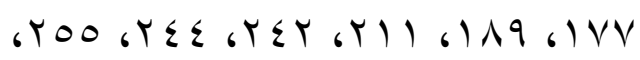
ד ו

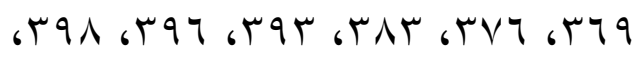

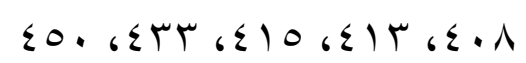

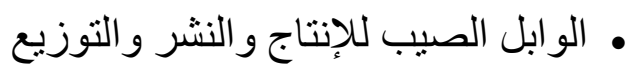
EY 64

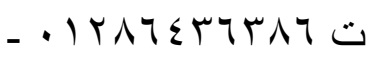

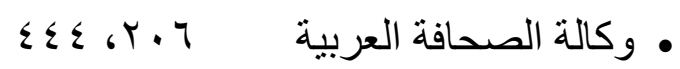
rqr 6) rq • مكتبة عبد الدايم 191 • مكتبة العربى للنشر و التوزيع or

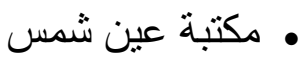 00

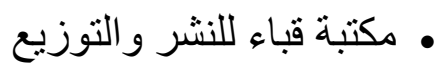
$\pi$

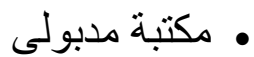 6I1 6) 91 6) YT 6

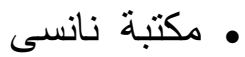 $r \leqslant 7$ ، $Y$.

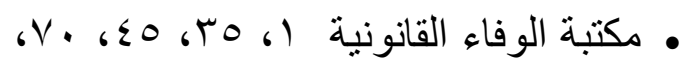
6100 6 10Y 6101 6). Y 6VA 6VV

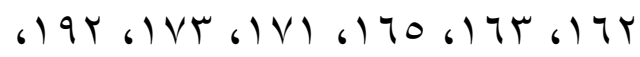
r. Y 6 Y Y 6 YTY 6 YO9 6 YY 6190 • مكتبة و هبه للطبع و النشر

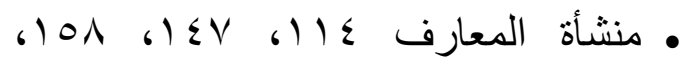
YTA 6 YTV 6 YOV 6) 1 .

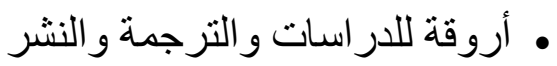
צו • مؤسسة تبانه ד 7 (، \&T० ، $\varepsilon \cdot r$

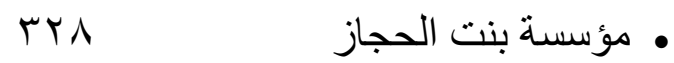

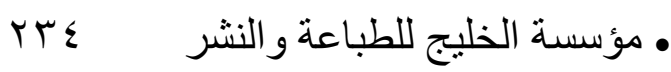
• مؤسسة شعلة الابداع للطباعة والنشر لـاعر النشر 4T) و التوزيع مؤسئ • مؤسسة الطوبجى للتجارة والطباعة rir و النشر مؤسن

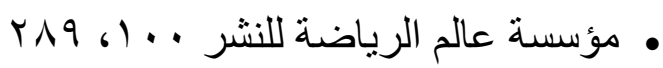

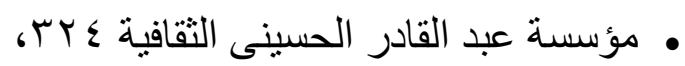

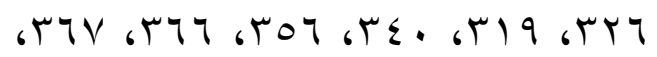
$\varepsilon \cdot V \cdot r V \varepsilon$ • مؤسسة هنداوى للتعليم و الثقافة

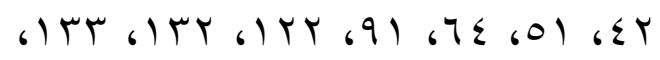
$r$.. . $Y q 1$ 